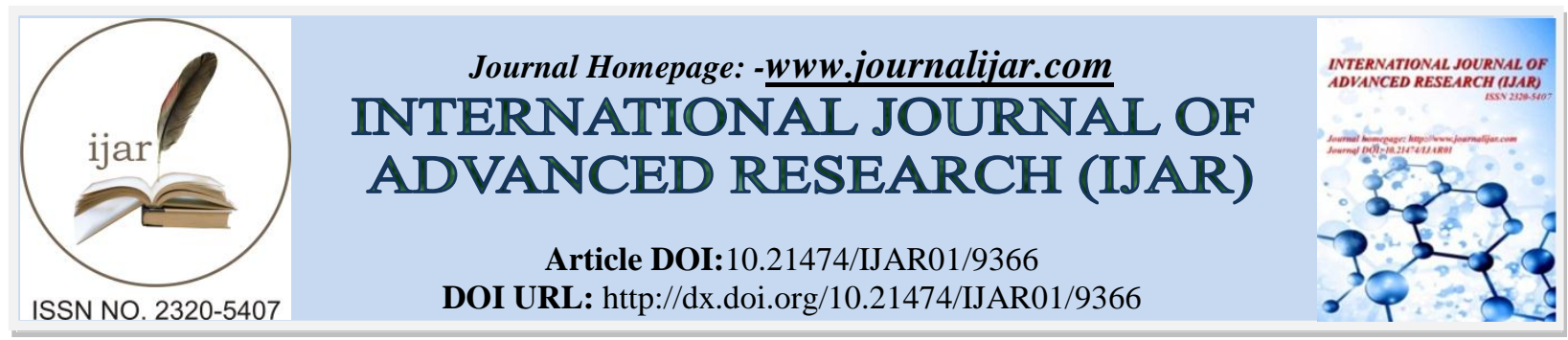

RESEARCH ARTICLE

\title{
EFFECTIVENESS OF STATIC STABILIZATION VERSUS DYNAMIC STABILIZATION OF CORE MUSCLES ON LOW BACK PAIN IN CYCLISTS - AN EXPERIMENTAL STUDY.
}

Seshagirirao Makke.

Shri Jagdishprasad Jhabarmal Tibrewala University,Rajasthan-333001.

\section{Manuscript Info}

\section{Manuscript History}

Received: 10 May 2019

Final Accepted: 12 June 2019

Published: July 2019

Key words:-

Static stabilization, Dynamic stabilization, Cycling and Low Back pain.

\begin{abstract}
Low back pain was shown to be a common cycling overuse injury. Development of LBP in cyclists suggests that a deactivation of the erector spinae and/or the multifidus muscles occurs as the spine maintains a flexed position during cycling. Simultaneous isometric cocontraction of the transverse abdominis and the multifidus muscles, while maintaining a neutral position of the spine, can ensure reeducation and reinforcement of the stabilization roles of these muscles. No studies were there on static versus dynamic stabilization exercises for core strength. 30 cyclists with low back pain were randomly placed into two groups, group A static stabilization exercises $(n=15)$, group $B$ dynamic stabilization exercises $(n=15)$. Both groups received training for 4 weeks with 10-20 repetitions twice daily. Baseline Pain, core strength and Quality of life (OSLBPQ) were recorded pre-treatment and post-treatment i.e. on end of 4th week and analyzed statistically by using VAS for pain, pressure biofeedback unit for core strength and Oswestry low back pain disability questionnaire for quality of life. The results revealed that Group B dynamic stabilization showed significant improvement than the Group A static stabilization with pain $(\mathrm{P}$ is 0.0031), core strength ( $\mathrm{P}$ is <0.0001) and Oswestry low back pain disability questionnaire ( $\mathrm{P}$ is 0.0297 ). Both stabilization exercises were found to be beneficial but when compared in between dynamic stabilization exercises showed better improvement in cyclists with low back pain.
\end{abstract}

Copy Right, IJAR, 2019,. All rights reserved.

\section{Introduction:-}

Cycling is generally regarded as a sport with great potential for fitness and rehabilitation (Burke ER 2002). There are no known studies that report the lifetime prevalence of low back pain (LBP) in cyclists. In addition to the limited research on the epidemiology of LBP in cyclists, there are also very few studies to determine the etiology of LBP in cyclists. LBP was shown to be a common cycling overuse injury. The point prevalence of LBP in cyclists ranged from 10-60\% (Mandy Marsden and Martin Schwellnus 2010).

The aim of the cyclist is to produce maximal power at the pedals to propel the bicycle forward. To maximize speed the cyclist must reduce aero-dynamic drag. This is achieved by maintaining a position of flexion of the hips and spine. This prolonged flexed posture may be an important factor contributing to the development of lower back pain

Corresponding Author:-Seshagirirao Makke, Research Scholar.

Address:-Shri Jagdishprasad Jhabarmal Tibrewala University, Rajasthan-333001. 
in cyclists as posterior active and passive spinal structures may be subjected to increased load and strain in this position (Usabiaga J et al 1997).

The bicycle "set-up" refers to the various adjustable parameters on the bicycle, including, amongst others, reach distance from seat to handle bars and saddle angle. These parameters must be adjusted relative to the cyclist's unique anthropometric measurements to ensure correct positioning of the cyclist on the bicycle (Burke ER 1994). It has been documented by various researchers that there is an association between LBP and frequent forward bending and prolonged sitting with the lumbar spine in a flexed position (Magora A.1973).

Spinal flexion is also associated with increased disc pressures. Cyclists are not stationary, and the lumbar spine also has to absorb inter-segmental joint reaction forces and moments that are generated by the lower limbs during pedaling. These forces and moments are transferred through the thoraco-lumbar spine while the trunk is in a flexed and sometimes rotated position (Nachemson, A.1966).

A number of hypotheses to explain the pathomechanics of cycling related lower back pain have been suggested. These hypotheses can be classified as: 1) the flexion relaxation hypothesis, 2) the muscle fatigue hypothesis, 3) over-activation of the spinal extensors hypothesis, 4) the mechanical creep hypothesis and 5) the disc ischemic hypothesis (Burnett AF, et al 2004).

Development of LBP in cyclists suggests that a deactivation of the erector spinae or the multifidus muscles occurs as the spine maintains a flexed position during cycling. As muscles relax, load is then shifted to the passive structures, such as the ligaments, and possibly the deeper muscles. Over-activation of the spinal extensor muscles may cause muscle contracture and increased tissue strain across the lumbar spine in cyclists. Mechanical creep may occur in the lumbar spine ligaments during prolonged sitting in a flexed position on a bicycle. The stretched static position that the lumbar spine remains in during cycling may reduce the normal mechanism for nutrients to enter the disc and metabolic waste to move out, and thus result in ischemic pain. Asymetrical firing patterns of the lumbar muscles on either side of the spine may affect spinal kinematics and support and therefore be a risk factor for LBP in cyclists (Floyd WF and Silver PH 1955).

Inhibition of the multifidus muscle has been shown to occur during static postures, especially into trunk flexion (Kevin P. Granata, et al 2005). Prolonged flexion for up to 20 minutes was enough to shut down the EMG activity of the lumbar multifidus for up to 7 hours (Jackson $M$ et al 2001). It is widely accepted that spinal stability is a crucial variable in lower extremity force output (Clair JM, et al 2009). Muscles such as multifidus and transverse abdominis have been implicated in dynamic spine stabilization (Moseley GL, et al 2002 and Hodges PW 2001).

Core strength and stability would be required to ensure cycling efficiency, in addition to contributing to the enhancement of the leverage from which cyclists generate power to the pedals (Asplund, C. Ross, M 2010 and Abt, $\mathrm{J}$ et al 2007). Core strengthening has become a global fitness trend that has filtered into world of sports medicine due to its numerous benefits, including improving athletic ability and preventing injury (Akuthota V, et al 2008). Improved core stability allows for highly coordinated muscle activation patterns to change continually, depending on the demands of the task at hand (McGill, SM et al 2003). Stable core allows for greater stability in the saddle, and as such, lower extremity alignment, which allows for greater transmission of forces from the torso to the lower extremity.

The stabilizing system (the core musculature) is responsible for providing sufficient stability to match varying demands that arise as a result of changes in posture, as well as changes in static and dynamic loads (Panjabi, MM. 1992). Core strengthening consists of activating trunk musculature which in turn should allow for improved performance of the axial and apendicular skeleton (Hibbs, AE. et al 2008).

The global stabilizing system includes the internal oblique, external oblique, rectus abdominis, gluteus maximus, lateral fibres of quadratus lumborum and portions of erector spinae. These are the larger, more superficial, torque producing muscles that enable an upright position. They are responsible for movement, as well as balancing and controlling external loads applied to the trunk, by reducing the resultant forces on the spine. The local stabilizing system includes the deep muscles and some deep portions of muscles, with insertions on the lumbar vertebrae. These muscles are responsible for maintaining lumbar posture and stability between the spinal segments. The multifidus muscle is considered to be part of the local system as it assists in segmental stabilization as a result of its vertebrae 
to vertebrae attachments. Similarly, the transverse abdominis is considered a key muscle in the local stabilizing system due to its direct attachment to the lumbar vertebrae via the thoraco-lumbar fascia and decussations with its opposite muscle in the midline (Richardson, C. et al 1999).

Activation of these muscles provides stabilization of the spine and efficient movement of the extremities, allowing transfer of power with minimal dissipation of energy and lack of adequate core strength may result in an inability of the athlete to generate extremity strength, resulting in decreased power and endurance (Kulandaivelan, $\mathrm{S}$ et al 2014).

Scientific studies have demonstrated molecular, biological, physiological and measurable improvements in skeletal muscle tissue after four weeks of a structured exercise program (Camera, DM et al 2010). Exercise involving cocontraction of the abdominal and lumbar component of the core assists in stabilization. Simultaneous isometric cocontraction of the transverse abdominis and the multifidus muscles, while maintaining a neutral position of the spine can ensure re-education and reinforcement of the stabilization roles of these muscles (Richardson, CA and Jull, GA 1995).

For the management of low back pain, exercise therapy has strong evidence for the reduction of pain and disability and return to work (Airaksinen O, et al 2006). Core training exercises focusing on the transverse abdominis and multifidus muscles can restore the lumbo-pelvic stabilization and can help to recovery from injury enhancing the spine (the lumbar and thoracic) and pelvis as well as the lower limb performance in static and dynamic functional tasks(Shamsi MB et al 2014). According to the previous recommendations, a staged approach will be administered to the stabilization exercise program (Koumantakis GA et al 2005).

Various number of studies are available in the literature on lumbar stabilization exercises for core strengthening in cycling athletes but no particular study is there on static stabilization and dynamic stabilization for core strengthening. Hence purpose of this study is to know the effectiveness of static stabilization versus dynamic stabilization of core muscles in decreasing low back pain in cyclists.

\section{Methodology:-}

1. Research method: Experimental method.

2. Research approach: Both qualitative and quantitative.

3. Research design: Experimental design.

4. Sampling technique: Simple random sampling

5. Sample size: 30 athletes, (15 in each group)

6. Duration of study: 4 weeks.

\section{Source of Data:}

This study is done at Shri JJT University Physiotherapy outpatient department, Rajasthan. The subjects will be considered for this study only after they signed on an approved consent form.

\section{Inclusion Criteria:}

1. Age group: $18-35$ years.

2. Gender: males only.

3. Cyclists with moderate low back pain and disability (2-8) on visual analogue scale.

4. Players willing to participate in the study.

\section{Exclusion Criteria:}

1. Acute back pain.

2. Disc herniation.

3. Recent fractures of lumbar vertebra.

4. Athletes under drug therapy.

\section{Outcome Parameters:}

1. Visual analogue scale for pain. (McCormack HM, 1988, Boonstra AM, 2008).

2. Pressure biofeedback unit for core strength measurement.(Pedro Olavo de Paula Limaa,2011). 
3. Oswestry low back pain disability questionnaire for quality of life. (Luzita I. Vela 2011, Davidson M 2002, Fairbank JC 2000).

\author{
Materials used for the study: \\ 1. Written informed consent \\ 2. Data collection sheet \\ 3. Treatment couch \\ 4. Exercise mat \\ 5. Physioball \\ 6. Pressure biofeedback unit
}

\title{
Procedure:-
}

Prior to the commencement of the procedure, written informed consent was taken from the participants. 30 cycling athletes were randomly allocated to two groups of fifteen (15) each. Randomized method by simple random sampling was used for the purpose of allocation of the subjects to the two groups. All the participants with low back pain who reported the complaints on field were screened for inclusion and exclusion criteria and then they were requested to participate in the study. Those willing to participate in the study were given a brief idea about the nature of the study and the intervention. Initial evaluation of pain intensity was done by VAS, core strength measured by using pressure biofeedback unit and quality of life was measured using Oswestry low back pain disability questionnaire as interventional outcome measures.

\section{Interventions:-}

Static stabilization exercises (Esha A. Bhadauria and Peeyoosha Gurudut 2017) :- Participants are advised,

1. Prone Bridging on Elbows - Lie on your stomach on a table or mat with your forearms/elbows on the table/mat; rise up so that you are resting on your forearms and toes; maintain abdominal draw in; your back should be completely straight; hold this position for $15 \mathrm{sec}-1 \mathrm{~min}$. Progress in increments of 15 seconds. Repeat 5-10 times.

2. Supine Abdominal Draw In - Lie on your back on a table or mat, knees up with feet flat on table/mat; pull the abs in and push your low back to the table/mat. Repeat 20 times.

3. Abdominal Draw In, Seated on Physioball - Begin by sitting on Physioball with your spine straight, knees at 90 degrees and your hands on your hips. Your feet should be shoulder width apart; draw in abdominal muscles and maintain this position for $3-5$ seconds. Repeat $10-20$ times.

4. Abdominal Draw In with feet on the ball - Lie on your back on table or mat with hips and knees bent to 45 degrees and your feet flat on the medicine ball; draw in abdominal muscles and maintain throughout exercise; hold for 3-5 seconds. Repeat $10-20$ times.

Dynamic stabilization exercises (Esha A. Bhadauria and Peeyoosha Gurudut 2017):- Participants are advised,

1. Prone Bridging on elbows with single leg hip extension - Lie on your stomach on a table or mat with your forearms/elbows on the table/mat; rise up so that you are resting on your forearms and toes; maintain abdominal draw in; your back should be completely straight; Now extend hip/leg upwards and hold, one leg at a time; alternate legs. Repeat 10-15 times each side.

2. Supine Butt Lift with Arms at Side - Lie on your back on table or mat with hips and knees bent to 90 degrees with feet flat on floor and arms palm-down at sides; draw in abdominal muscles and maintain throughout exercise; slowly raise your butt off the table/mat by using your gluteals and hamstrings until your torso is in line with thighs; hold for 3-5 seconds. Repeat $10-20$ times.

3. Abdominal Draw In, Seated on Physioball with leg extension - Begin by sitting on Physioball with your spine straight, knees at 90 degrees and your hands on your hips. Your feet should be shoulder width apart; draw in abdominal muscles and maintain this position throughout the exercise. Begin by slightly lifting your right or left knee and perform a leg extension hold for $3-5$ second count; keeping hips level then alternate repeating on opposite side. Repeat $10-20$ times on each side.

4. Abdominal Draw In with feet on the ball- add movement - Lie on your back on table or mat with hips and knees bent to 45 degrees and your feet flat on the medicine ball; draw in abdominal muscles and maintain throughout exercise; hold for 3-5 seconds. As you tilt your hips back raise your butt about 2 to 3 inches maximum off the floor. Hold this position for $3-5$ seconds; slowly bring your butt back to start. Repeat $10-20$ times. 
Group A received Static stabilization exercises, Group B Dynamic stabilization exercises. All subjects in both groups performed each exercise for 3-5 seconds hold for 10-20 repetitions for 4 weeks (twice daily). Data were analyzed statistically by using students $t$ test and one way analysis of variance, Anova.

\section{Results:-}

The results revealed that pre post analysis in both the groups showed extremely significant improvement in terms of pain \& Core strength and quality of life $(\mathrm{p}<0.0001)$. Whereas when between groups was analyzed, Group B dynamic stabilization showed significant improvement than the Group A static stabilization with pain (P is 0.0031), core strength ( $\mathrm{P}$ is <0.0001) and Oswestry low back pain disability questionnaire ( $\mathrm{P}$ is 0.0297 ).

Graph 1:-of post treatment values of VAS in both Static \& Dynamic Groups

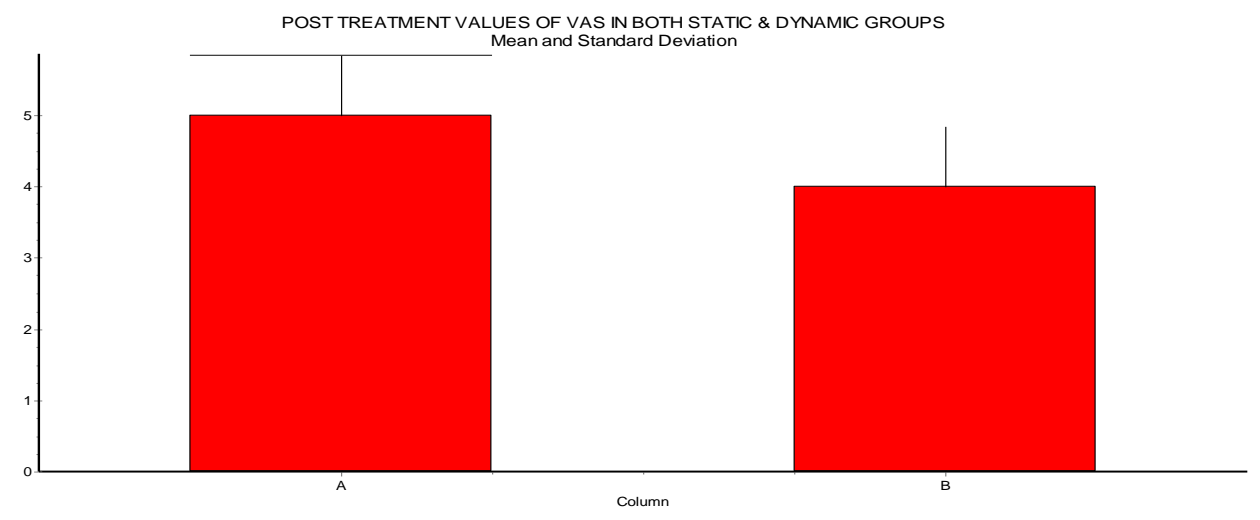

Table1:-Representing statistical measures of VAS in static and dynamic group

\begin{tabular}{|l|l|l|}
\hline & static group & dynamic group \\
\hline Mean & 5.000 & 4.000 \\
\hline s.d & 0.8452 & 0.8452 \\
\hline s.error & 0.2182 & 0.2182 \\
\hline Median & 5.000 & 4.000 \\
\hline p-value & 0.0031 & \\
\hline
\end{tabular}

Graph 2:-of post treatment values of core strength in both static \& dynamic groups

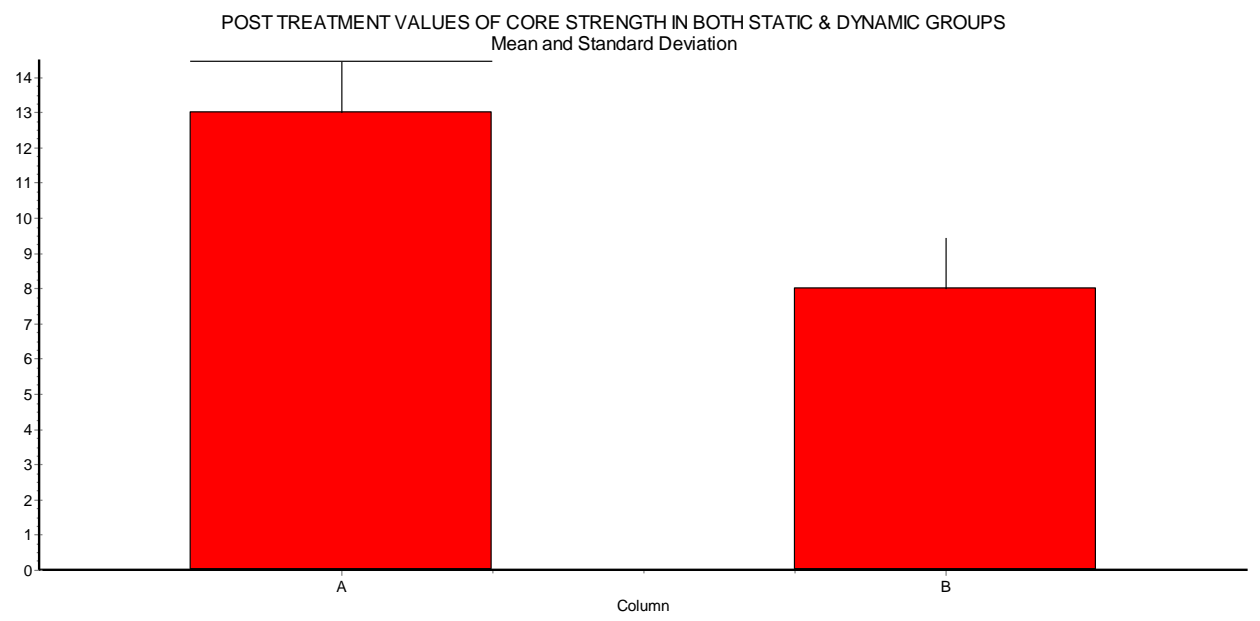

Table 2:-representing statistical measures of core strength in static and dynamic group static group dynamic group 


\begin{tabular}{|l|l|l|}
\hline Mean & 13.000 & 8.000 \\
\hline s.d & 1.464 & 1.464 \\
\hline s.error & 0.3780 & 0.3780 \\
\hline Median & 13.000 & 8.000 \\
\hline p-value & $<0.0001$ & \\
\hline
\end{tabular}

Graph 3:-of post treatment values of ODI in both static \& dynamic groups

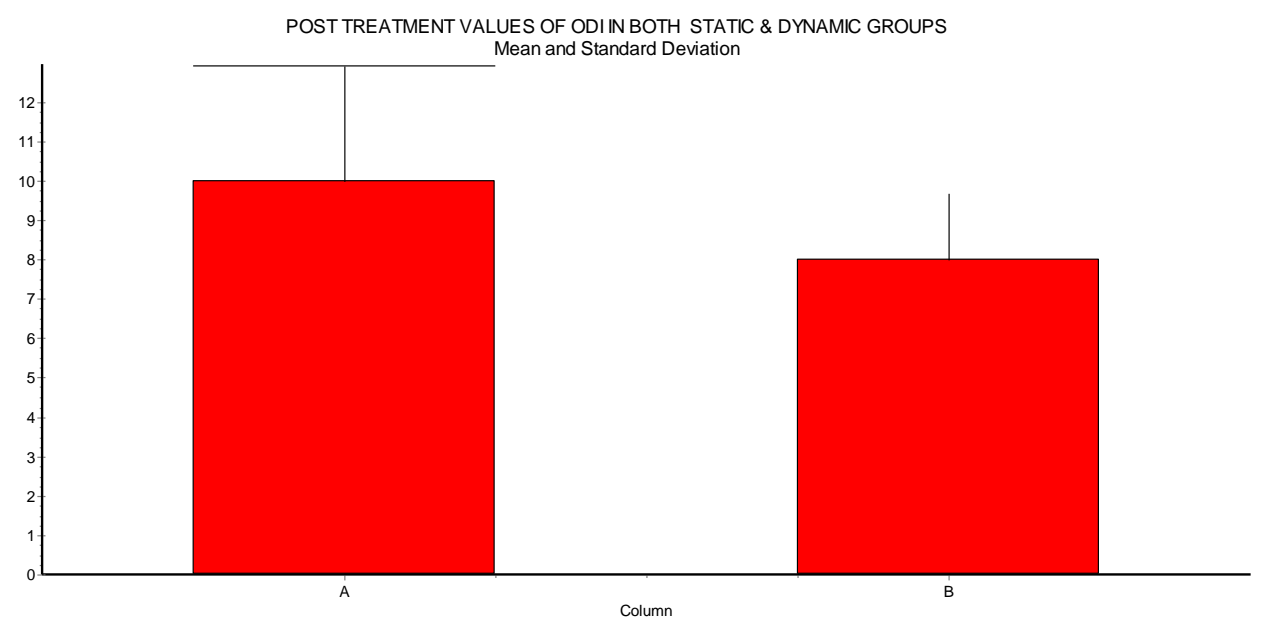

Table 3:-representing statistical measures of ODI in static and dynamic group

\begin{tabular}{|l|l|l|}
\hline & static group & dynamic group \\
\hline Mean & 10.000 & 8.000 \\
\hline s.d & 2.928 & 1.690 \\
\hline s.error & 0.7559 & 0.4364 \\
\hline Median & 10.000 & 8.000 \\
\hline p-value & 0.0297 & \\
\hline
\end{tabular}

\section{Discussion:-}

The purpose of this study was to compare static stabilization exercises and dynamic stabilization exercises in decreasing low back pain, improving core strength and quality of life in cyclists with low back pain. Dynamic stabilization group showed significant improvement than the static stabilization group with pain ( $\mathrm{P}$ is 0.0031 ), core strength ( $\mathrm{P}$ is <0.0001) and Oswestry low back pain disability questionnaire ( $\mathrm{P}$ is 0.0297$)$.

There are many articles in the literature that promote core training programmes and exercises for performance enhancement without providing a strong scientific rationale of their effectiveness, especially in the sporting sector. In the rehabilitation sector, improvements in lower back injuries have been reported by improving core stability. Few studies have observed performance enhancement in sporting activities despite observing improvements in core stability and core strength following a core training programme (Hibbs, AE, et al 2008).

Appropriate rehabilitation program focused on trunk and core musculature stability exercise addressing to sport related specific demands, should be considered as an optimal conservative method in the multidisciplinary approach for treatment of groin pain and prior to any surgical intervention (Dello Iacono, et al 2017).

The findings of Abt et al., (2007), are supported by Asplund and Ross (2010) who also indicated that the strength of the abdominal muscles is vital in maintaining a stable pelvic position. It was suggested that strengthening of these muscles could lead to improved pedaling efficiency. They also suggested that the leverage from which cyclists generate power may be enhanced as a result of improved core stability. Activation of these muscles provides stabilization of the spine and efficient movement of the extremities, allowing transfer of power with minimal 
dissipation of energy and suggested that a lack of adequate core strength may result in an inability of the athlete to generate extremity strength, resulting in decreased power and endurance which supports core stabilization exercises in this study.

Core stabilization exercises were found to be more effective in reducing pain and improving functional status by decreasing disability of patients with non-specific low back pain in comparison with conventional exercises. (Inani, Sumit B and Selkar, Sohan P 2013).

Lumbopelvic stabilization training may provide therapeutic effects by inducing pain modulation through an improvement in the pain threshold and reduction in pain intensity. Lumbopelvic stabilization training may be considered as part of the management programs for treatment of chronic low back pain.(Paungmali, Aatit, et al, 2017).

Paungmali et al 2018, Lumbar core stabilization exercise could possibly influence plasma endorphins but not plasma cortisol levels among patients with chronic nonspecific low back pain. The mechanism of action of the painrelieving effect of LCSE might be related to an endogenous opioid mechanism as part of its effects and might not be involved with a stress-induced analgesia mechanism are similar to the current study in decreasing pain.

Segmental stabilization is superior to superficial strengthening for all variables which does not improve transverse abdominis activation capacity. (Fabio Renovato Franca, et al 2010).

Exercise programs to improve core stability should focus on muscle activation, neuromuscular control, static stabilization, and dynamic stability. Core stabilization relies on instantaneous integration among passive, active and neural control subsystems. Core muscles are often categorized functionally on the basis of stabilizing or mobilizing roles. Neuromuscular control is critical in coordinating this complex system for dynamic stabilization. (Huxel Bliven et al 2013).

Static bracing of the core was achieved using a modified "plank" position, with and without a Swiss ball, and held for 30 seconds. A mechanically similar "plank" was then held using suspension straps, suspension training noticeably improves engagement of anterior core musculature when compared with both lateral and posterior muscles (Atkins et al 2015) supports static stabilization exercises in improving core function.

Anticipatory postural adjustment times for eternal oblique, transverse abdominis/internal oblique and erector spinae were shorter in the dynamic neuromuscular stabilization group than in the conventional core stabilization group but Falls Efficacy Scale remained stable through the 2-year follow-up period only in the dynamic neuromuscular stabilization group. (Lee et al 2018) supports dynamic stabilization exercises as treatment form for long term benefit.

Compared with that of the active muscular component, the contribution of the passive elements to stability is quite small, lumbar spine may experience compressive loads during activities of daily living and still maintain stability. (Hyun Lee and Ji Heon Hong 2016).

Without active support, the osteo-ligamentous lumbar spine becomes unstable under compressive loading of only 90 $\mathrm{N}$. Therefore the active muscular components of this system are critically important (Crisco JJ et al 1992), similar in this study like dynamic stabilization exercises are more beneficial for better core functioning.

These studies support the hypothesis that a strong core will improve pelvic stability, thereby decreasing the loss of force through twisting of the trunk and improving the force distribution to the lower extremities, which would in turn lead to improved pedaling efficiency which are similar to this study that both static and dynamic stabilization exercises showed improvement in decreasing low back pain in cyclists whereas dynamic stabilization exercises in long term follow up would definitely built up a strong core stability in athletes.

\section{Conclusion:-}

The results of this study showed significant reduction in pain and increase in core strength and improvement in quality of life in cyclists, when static and dynamic stabilization exercises were performed over 4 weeks of treatment 
time. Therefore both exercises were found to be beneficial but when compared in between dynamic stabilization exercises showed better improvement in cyclists with low back pain.

\section{Limitations:}

1. It is a short duration study.

2. Sample size was small.

3. Only males considered for this study.

4. Cycling types may have been taken into account.

\section{Recommendations for generalizing the results:}

1. Long duration study can to be done.

2. Large sample can be taken.

3. Both males and females can be included in the study.

4. Specific cycling types can be considered during the study for generalizing the results.

\section{References:-}

1. Abt, J., Smoliga, JM., Brick, MJ., Jolly, JT., Lephart, SM. and Fu, FH (2007). Relationship between Cycling Mechanics and Core Stability. Journal of Strength and Conditioning Research, 21(4): 1300-1304.

2. Airaksinen O, Brox JI, Cedraschi C, Hildebrandt J, Klaber-Moffett J, Kovacs F and Zanoli G (2006). Chapter 4 European guidelines for the management of chronic nonspecific low back pain. Eur Spine J,15:s 192-300.

3. Akuthota, V., Ferreiro, A., Moore, T. and Fredericson, M (2008). Core Stability Exercise Principles. Current Sports Medicine Reports. 7(1): 39-44.

4. Asplund, C and Ross, M. (2010). Core Stability and Bicycling. Current Sports Medicine Reports. 9(3): 155-160.

5. Atkins, Stephen J; Bentley, Ian; Brooks, Darrell; Burrows, Mark P; Hurst, Howard T and Sinclair, Jonathan K (2015). Electromyographic response of global abdominal stabilizers in response to stable and unstable base isometric exercise.Journal of Strength and Conditioning Research - Volume 29 - Issue 6 - p 1609-1615.

6. Boonstra AM, Schiphorst Preuper HR, Reneman MF, Posthumus JB and Stewart RE (2008). Reliability and validity of the visual analogue scale for disability in patients with chronic musculoskeletal pain. Int J Rehabil Res,31(2):165-9.

7. Burke ER (1994). Proper fit of the bicycle. Clin Sports Med;13: 1-14.

8. Burke ER (2002). Serious cycling. USA: Human Kinetics,1-248.

9. Burnett AF, Cornelius MW, Dankaerts W and O'Sullivan PB (2004). Spinal kinematics and trunk muscle activity in cyclists: A comparison between healthy controls and non-specific chronic low back pain subjects-A pilot investigation. Man Ther; 9:211-219.

10. Camera, DM., Anderson, MJ., Hawley, JA. and Carey, AL (2010). Short-term endurance training does not alter the oxidative capacity of human subcutaneous adipose tissue. European Journal of Applied Physiology. 109(2) 307-316.

11. Clair JM, Okuma Y, Misiaszek JE and Collins DF (2009) Reflex pathways connect receptors in the human lower leg to the erector spinae muscles of the lower back. Experimental Brain Research 196: 217-227.

12. Crisco JJ, Panjabi MM, Yamamoto I and Oxland TR (1992): Euler stability of the human ligamentous lumbar spine: II. Experiment. Clin Biomech (Bristol, Avon);7:27-32.

13. Davidson M and Keating JL (2002). A comparison of five low back disability questionnaires: reliability and responsiveness. Physical Therapy; 82:8-24.

14. Dello Iacono, Antonio; Maffulli, Nicola; Laver, Lior and Padulo, Johnny (2017). Successful treatment of groin pain syndrome in a pole-vault athlete with core stability exercise. J Sports Med Phys Fitness. Dec;57(12):1650-1659.

15. Esha A. Bhadauria and Peeyoosha Gurudut (2017). Comparative effectiveness of lumbar stabilization, dynamic strengthening, and Pilates on chronic low back pain: randomized clinical trial. Journal of Exercise Rehabilitation;13(4):477-485.

16. Fabio Renovato Franca, Thomaz Nogueira Burke, Erica Sato Hanada and Amelia Pasqual Marques (2010). Segmental stabilization and muscular strengthening in chronic low back pain - a comparative study. Clinics;65(10):1013-1017.

17. Fairbank JC and Pynsent PB (2000). The Oswestry Disability Index. Spine,25(22):2940-2953.

18. Floyd WF and Silver PH (1955). The function of the erectores spinae muscles in certain movements and postures in man. J Physiol;129:184-203.

19. Hibbs, AE., Thompson, KG., French, D. Wrigley and A. Spears, I (2008). Optimizing Performance by Improving Core Stability and Core Strength. Sports Medicine. 38(12): 995-1008. 
20. Hodges PW (2001) Changes in motor planning of feed forward postural responses of the trunk muscles in low back pain. Exp Brain Res 141: 261-266.

21. Huxel Bliven, Kellie C and Anderson, Barton E (2013). Core stability training for injury prevention.. Sports Health A Multidisciplinary Approach5(6):514-22.

22. Hyun Lee and Ji Heon Hong (2016), Comparison of trunk muscle activities in lifting and lowering tasks at various heights.J Phys Ther Sci. Feb; 28(2): 585-588.

23. Inani, Sumit $B$ and Selkar, Sohan P (2013). Effect of core stabilization exercises versus conventional exercises on pain and functional status in patients with non-specific low back pain: a randomized clinical trial..J Back Musculoskelet Rehabil;26(1):37-43.

24. Jackson M, Solomonow M, Zhou B, Baratta RV and Harris M (2001). Multifidus EMG and tension-relaxation recovery after prolonged static lumbar flexion. Spine (Phila Pa 1976) 26: 715-723.

25. Kevin P. Granata, Ellen Rogers, and Kevin Moorhouse (2005). Effects of Static Flexion-relaxation on Paraspinal Reflex Behavior. Clin Biomech (Bristol, Avon); 20(1): 16-24.

26. Koumantakis GA, Watson PJ and Oldham JA (2005). Trunk muscle stabilization training plus general exercise versus general exercise only: randomized controlled trial of patients with recurrent low back pain. Phys Ther; 85(3):209-25.

27. Kulandaivelan , S.; Chaturvedi , R. and Moolchandani , H (2014). Efficacy of progressive core strengthening exercise on functional endurance tests and hypertrophy of multifidus, transverses abdominis in healthy female subjects with low core endurance. Journal of Exercise Science and Physiotherapy, Vol. 10 No. 2: 114-121.

28. Lee, Nam G; You, Joshua Sung H; Yi, Chung H; Jeon, Hye S; Choi, Bong S; Lee, Dong R.... Yoon, Hyun S (2018). Best Core Stabilization for Anticipatory Postural Adjustment and Falls in Hemiparetic Stroke.apmr. 01.027

29. Luzita I. Vela, Douglas E. Haladay and Craig Denegar (2011). Clinical Assessment of Low-Back-Pain,Treatment Outcomes in Athletes. Journal of Sport Rehabilitation, 20, 74-88.

30. Magora A (1973). Investigation of the relation between low back pain and occupation: Physical requirements: Bending, rotation, reaching and sudden maximal effort. IMS Ind Med Surg, 5: 186-190.

31. Mandy Marsden and Martin Schwellnus (2010). Lower back pain in cyclists: A review of epidemiology, pathomechanics and risk factors. International SportMed Journal, Vol.11 No.1, pp.216-225.

32. McCormack HM, Horne DJ and Sheather S (1998). Clinical applications of visual analogue scales: a critical review. Psychol Med;18(4):1007-19.

33. McGill, SM., Grenier, S., Kavcic, N. and Cholewicki, J (2003). Co-ordination of Muscle Activity to Assure Stability of the Lumbar Spine. Journal of Electromyography and Kinesiology. 13(4): 353-359.

34. Moseley GL, Hodges PW and Gandevia SC (2002) Deep and superficial fibers of the lumbar multifidus muscle are differentially active during voluntary arm movements. Spine 27: E29-36.

35. Nachemson, A (1996). The load of lumbar discs in different positions of the body. Clin Orthop; 45, 107-122.

36. Panjabi, MM (1992). The Stabilizing System of the Spine. Part 1. Function, Dysfunction, Adaption and Enhancement. Journal of Spinal Disorders. 5(4): 383-389.

37. Paungmali, Aatit; Joseph, Leonard Henry; Punturee, Khanittha; Sitilertpisan, Patraporn; Pirunsan, Ubon; Uthaikhup, Sureeporn (2018) a. Immediate Effects of Core Stabilization Exercise on beta endorphin and cortisol Levels among Patients with chronic nonspecific Low Back Pain: A Randomized Crossover Design.Volume 41, Issue 3, Pages 181-188.

38. Paungmali, Aatit; Joseph, Leonard Henry; Punturee, Khanittha; Sitilertpisan, Patraporn; Pirunsan, Ubon; Uthaikhup, Sureeporn (2017) b. Lumbopelvic Core Stabilization Exercise andPain Modulation Among Individuals withChronic Nonspecific Low Back Pain. Pain Pract;17(8):1008-1014. doi: 10.1111/papr.12552.

39. Pedro Olavo de Paula Limaa, Rodrigo Ribeiro de Oliveira a, Leonardo Oliveira Pena Costa b and Gloria Elizabeth Carneiro Laurentino c (2011). Measurement properties of the pressure biofeedback unit in the evaluation of transversus abdominis muscle activity: a systematic review. Physiotherapy 97; 100-106.

40. Richardson, CA and Jull, GA (1995). Muscle control - pain control. What exercise would you prescribe? Manual Therapy. 1: 2-10.

41. Richardson, CA, Jull, G., Hodges, P. and Hides, J (1999). Therapeutic Exercise for Spinal Segmental Stabilization in Low Back Pain - Scientific Basis and Clinical Approach. Edinburgh: Churchill Livingstone.

42. Shamsi MB, Sarrafzadeh J and Jamshidi A (2014). Comparing core stability and traditional trunk exercise on chronic low back pain patients using three functional lumbopelvic stability tests. Physiother Theory Pract;31(2):89-98.

43. Usabiaga J, Crespo R, Iza I, Aramendi J, Terrados N and Poza JJ(1997). Adaptation of the lumbar spine to different positions in bicycle racing. Spine;22: 1965-1969. 